SIR-With reference to the letter from S.J. Starkie (Nature 318, 406; 1985), it is clear that freedom of will must be narrowly limited by our bodily structure and experience, but complete determinism is not credible. I can easily decide that I am so bad at guessing the interest of letters in Nature by reading their titles that I would do better to find a method of making a genuinely chance selection. For example, I could set up a Geiger counter in a background giving an average of 20 counts a minute. Then, starting from an arbitrary time, I could record the times of occurrence of the next ten clicks. If the first occurred after 2 seconds I would read the first letter starting after 2 pages from the last Article: if the next click occurs at 7 seconds I would read the first letter starting after page 7 , and so on. I would have surrendered any possible freedom of will in exchange for a programme based on a series of fundamentally indeterminate events. A newly qualified doctor could use an exactly similar method to decide in which continent he would look for his first job.

Even without such an unlikely way of making decisions, it is oversimplifying to say that either our thoughts or our actions are directly determined in any simple way by our structure and experience. Experiences are inaccurately and incompletely recorded, and the older records must have been damaged by the destruction of critical parts of cells by unpredictable fast electrons or alpha particles from randomly occurring radioactive decays from our natural radioactive background. And of

\section{If (1986)...}

\section{SiR-}

If you concede that something in the Cosmos Determines every move you make on Earth, And not resist its force but match its purpose And tread the path laid down for you from

birth;

If you are true to Self (as Jung and Shakespeare And sundry other schools, I think, agree) Instead of to some norm of "right" behaviour Or someone else you think you'd rather be; If you will grant your favourite conviction Will only take you far away from home And, though it send you in the same direction, Can only land you back where you ran from; If you allow that, solid as you stand there, You are no more than a character in a tale, Of the same stuff as fantasy and dreams are, Enacted on a universal scale,

Then you will unequivocally see

That Entropy and Order are all One,

And know how good it feels to live life free And, which is more....

$$
\text { .... you will be a god, my son. }
$$

Keith Dixon

Bankside,

Clapham Station,

via Lancaster, UK course our thoughts and decisions can be affected only by what remains of the records, not by the experiences themselves.

This is a triviality; however much damaged the records are, they could still determine our thinking.

Like most people, I feel that I have some freedom of will, but this feeling itself could have been programmed into me by the records of past events. While I may be programmed to think erroneously that I have some degree of free will, many of those who have thought deeply on the subject believe - or perhaps I should say are programmed to believe - that they have not. They may of course be right; but I find it difficult to accept that a rigidly determined belief in rigid determination can be a valid proof that this is how the world actually is; the argument has an undesirably circular smell.

What I am quite certain of is that we cannot get any further by talking about the problem, any more than we could have foretold the production of monoclonal antibodies by talking about heredity and immunity.

Any experimental investigation must start with a detailed study of our conscious awareness. Our consciousness is, in biological terms, very expensive. The temperature and concentrations of a great variety of substances in our brains have to be controlled far more closely than they need to be to keep the body and most of the nervous system fully operational. We should not have evolved the necessary high quality stabilization systems if consciousness were unimportant to our survival. The survival can have depended only on what we did, not on what we thought about what we did, so our consciousnesses cannot have been simply epiphenomena without practical influence. During the long and climatically uniform period of the Cretaceous, there could have been little advantage to an individual in diverging from the built-in instinctive behaviour that had been optimized by selection over several million years.

The sudden and permanent change of environment hypothesized to have resulted from the impact of an asteroidal body at the end of the Cretaceous period would, however, have made much of the built-in programmes inappropriate to the new conditions, and individual or group experience could often have offered a better guide to action. For this to be useful, it would have been essential to have a mechanism for deciding whether to follow the inherited programme or a new programme based on experience. I believe that our conscious awareness, useless to a creature whose behaviour was hereditarily determined, developed as the organ of choice.
When we have gained a full understanding of the way in which some ten thousand million cells, with their complex multiple interconnections, can support a single apparently unitary conscious awareness, and when we have learned how the brain so promptly finds and presents the relevant memories to the consciousness to make optimum choices possible, we can begin again seriously to discuss free will.

I expect that we shall find that our decisions are largely determined by the records of our experiences, together with a sizeable contribution from hereditarily built-in motivations, and with a random element arising from the fact that all of the records are fuzzy round the edges. When all of these components have been recognized and allowed for, we can usefully re-examine the nature, if any, of our "freedom".

46 Vernon Road,

J.H. FREMLIN

Edgbaston,

Birmingham B16 9SH, UK

SIR-Apparently one of the most deterministic aspects of human neural functioning is a compulsion to argue about free will. The recent letter by D.H. Evans ( $\mathrm{Na}$ ture 317,$762 ; 1985$ ) claims that because the synaptic interactions among an array of neurones is far from thermodynamic equilibrium, "entropy production makes it impossible for the brain function of free will to be determined" since "causes are lost in this increase of entropy . . . as far as predicting the future is concerned". On the contrary, much behaviour is predictable despite mediation through nonequilibrium neural interactions: a host of perceptual, motor and reflex actions can be reproducibly elicited by peripheral and central stimulation.

More to the point is recognition that free will does not reflect the absence of a causal network, from increasing entropy or quantum indeterminacy of synaptic contacts or whatever. Free will implies that our volitions (a wish to argue neuroscience, to write a letter to Nature) causally determine certain of our actions (arguing, writing). Indeed, if such actions are not strictly determined, having these volitions would be futile. And insofar as non-equilibrium neural arrays must translate these volitions, they too must be deterministic.

The question remains, of course, as to how our volitions arise. Introspection suggests that these do not arise randomly, but that they too have causes. Free will does not imply an indeterminate or probabilistic selection, but a causally-determined choice.

JOSEPH D. ROBINSON

Department of Pharmacology,

SUNY Upstate Medical Center,

Syracuse, New York 13210, USA 